\title{
The Conception and Perception of Traditional/Contemporary Urban Space About the City: Theory of Representation vs. Everyday Practices
}

\author{
Ana Rusta \\ French-Albanian School "Ernest Koliqi", \\ Tirana, Albania
}

Doi: 10.1515/ajis-2017-0027

\begin{abstract}
In this essay will be given a great importance to the traditional and contemporary conception and perception of urban space as elements referred to the city. Throughout the analysis, in the level of the contemporary perception of the city, will be presented the theory that insists on the conception and construction of urban space by the practices of everyday life and the so-called strategy of resistance. This refers not only to a new frame of sociology but also to a new methodological approach for the construction of the urban space. Regarding the latter, will be elaborated the thought of Henri Lefebvre and Michael De Certeau as a vector for the explanation of some problems observed in the methodological conception of urban space such as the city of Tirana. Through this approach, we will specifically disclose some problems observed about the use of certain urban spaces. Traditionally, the theory of representation emphasizes a conception of abstract and rational presentation of urban space analyzed from above, giving us an incredibly simplified bureaucratic view of the city. This theory does not analyze specifically micro-urban space and social problems facing the people in this space. Therefore, a new contemporary theory appears as a critique which aims to use a new anti-bureaucratic method that starts from the study of practices of everyday life, using instrumental analysis of the body and micro-social practices to present urban space in the most comprehensive frame.
\end{abstract}

Keywords: practices of everyday life, strategy of resistance, theory of representation, city, body

\section{Introduction}

Thanks to the numerous consequences of the phenomenon of urbanization and suburbanization in urban areas, and on the basis of multiple interests (political, social, economic, cultural, etc.) that, the concept of urban planning have been highlighted as a concept of paramount importance. However, to concretize this process, it is necessary to select in advance both theoretical and practical ways and methods. This means that urban planning and numerous and varied projects derived from this process should not be limited to practical, but also theoretical and conceptual aspects. In this optic, two methodological perspectives regarding the conception of the city about the respective positive and negative aspects will be addressed. More specifically, the case of the city of Tirana will be addressed and the concrete consequences of the implementation of the theory of representation, as well as the emergence of a new perspective, described as practices of everyday life, forming a different perception and conception of the city.

\section{Methodology}

The method used is a qualitative research. The essay is largely based on some important works of sociologists such as Henri Lefebvre and Michel De Certeau. Through a comparative and analytic 
approach, we will analyze the differences between the theory of representation and the theory of daily life practices.

The purpose of the analysis is to explain that the two approaches not only explain but also construct the same urban space in distinct ways. As a concrete case, we will analyze the city of Tirana to see how the methodological application of the theory of representation has caused some negative consequences and how the use of everyday life practices theory can minimize these consequences by designing the urban space in a more concrete and human dimension.

\section{Perspective of the Theory of Everyday Life Practices and Its Criticisms}

One of the most popular theoretical and practical perspectives concerning the conception of the city states that its perception and conception should be based on a practical and non-laboratory ground: it has to rely on practices of everyday life that people encounter and do in the city. One of the theories that supports this approach is the so-called the theory of everyday life practices (nonrepresentational theory). The latter emphasizes and focuses its interest not so much on abstractionmental representation but on everyday practices that shape the behavior of individuals against others and themselves. This approach criticizes the knowledge that is based on the representational theory and technical treatment of urban space by bureaucratic planners, leaving aside human needs and capital. - Thus, "the planning of these administrators [is] linked to the public (State) sector. It sees itself as scientific. It relies sometimes on a science, sometimes on studies which call themselves synthetic (plural or multidisciplinary). This scientism, which accompanies the deliberate forms of operational rationalism, tends to neglect the so-called 'human factor'" (Lefebvre, 1996: 83).

If we analyze more concretely the case of the city of Tirana, we have historically noted that the city has mainly shaped the urban spaces through an abstract-rational representation designed by the formal landscaping plans with upward view (from the air). But this is an approach that has characterized not only Tirana, but also other cities in different countries. "Planning has conventionally been seen as an application of technical expertise to competing claims for the city. The planner, a professional public servant, makes disinterested judgments in the public interest, reconciling demands for growth with the needs of a city's publics" (Hall, Hubbard \& Short, 2008: 318). In this regard, the treatment of urban space in Tirana is conceived merely as a physicaltechnical habitat excluding the social relationships and dynamics found in the daily life practices of the city ${ }^{1}$. Many scholars think that relying only on the organizational-bureaucratic power of urban space has led to neglecting the spheres of everyday life in the city. This situation characterizes especially the city of Tirana where the conception of the vast part of the urban space as residential space has created a significant gap and disadvantage for other social activities and social practices. Consequently, often at the level of social conflict of urban space "there is a violent clash between urban reality and industrial reality...This dialectical process, far from being clear, is also far from over. Today it still provokes 'problematic' situations" (Lefebvre, 1996: 70). It is precisely in this difficult situation that the expansion of housing and the increase in the penetration of the city into the physic territory have created a constructivist perspective capable of combining the sense of reality with the possibility of space as a dynamic and heterogeneous unit. Contemporary urban space scholars are increasingly revealing the concept of 'liberated community', which means liberation from the sprawl of space through returning attention to the community. Today, conceptually - "....the central concern of [urbanists] is with the concept of the public realm and how this is constituted in practice. It is the space where use-values predominate and people lead their

\footnotetext{
1 "In order to describe, represent and plan the territory, some disciplines and some practices look at the city from a zenith vision, with a top-down approach, from the tower to the ground or through maps and satellite pictures. These images, however, do not seem to be tools adequate enough to understand the characteristics of urban settings; to record the rhythms, movements, flows and the perceptive sequences of places" - Henckel D., Thomaier S., Könecke B., Zedda R., Stabilini S. (Eds.) (2013). Space-Time Design of the Public City. Springer: Netherlands,pp. 4
} 
daily lives (Inam, 2014: 7).

Further, this initiative has brought about a shift of the boundaries between city and territory not only in the physical but also in the psychic dimension of social relationships. In this context, scholars such as De Certeau mark a distinction between place and space ${ }^{2}$.

So everyday life in the city reveals all the ways of practical adaptation through practical negotiation between residents, pointing to situations that cannot be expressed verbally and that make sense through nonverbal actions (behavior, body language, gestures, etc.). In this way, shifting from theory to practice becomes decisive when scholars classify urban spaces as personified and lived and not simply imagined and presented abstractly. "In short, space is a practiced place. Thus the street geometrically defined by urban planning is transformed into a space by walkers". (De Certeau, 1984: 117). We note by analyzing non-verbal and non-discursive behaviors that people create their identities through simple acts such as walking, jumping, running, etc.

\section{Read and Perceive Urban Spaces Through the 'Body'}

As a result of focusing on day-to-day social practices in urban space, today's scholars praised the "body" and its rhythm as fundamental, as the main media of sociological analysis. As Amin and Thrift underlines, "the study of urban rhythms is becoming important in contemporary urbanism.... The rhythms of the city are the coordinates through which inhabitants and visitors frame and order the urban experience... Rather, the city is often known and negotiated through these rhythms and their accompanying ordering devices (traffic rules, telephone conventions, opening times, noise control codes).... The metaphor of city rhythms can highlight neglected temporalities" (Amin \& Thrift, 2002: 17). So the 'body' was praised as a vector that emphasized the fact that one cannot think about the city without understanding the way it is experienced and 'spotted' through the body. In this regard, De Certeau states that "history begins at ground level, with footsteps" (Ward, 2000: 105). But in these urban routines, the urban body is seen as a subject of social control through power strategies, and that practices different tactics as a source of resistance ${ }^{3}$. Developing this logic, De Certeau emphasized the act of walking as a tactic and resistance act, describing it as a process in which passers-by criticize official power strategies through a particular discourse typology. According to him, "it thus seems possible to give a preliminary definition of walking as a space of enunciation" (De Certeau, 1984: 98). Through the walking, the idea is that pedestrians can practically seek ways to reject, suspect, respect etc., an aspect of the social and moral order unfolded in the urban space. Therefore "walking affirms, suspects, tries out, transgresses, respects, etc., the trajectories it 'speaks' " (De Certeau, 1984: 99). One of the examples is that of marginalized social groups, minority communities or ecological protests that appear through urban spaces. Consequently, these forms of resistance are termed as tactics and as part of a counterculture that belongs to others. In this optical, De Certeau ".... sees tactics transforming the places designed by hegemonic powers and envisioned as the neat and orderly realm of the concept city, into unruly spaces; that is, he sees practices as spatialising places" (Hubbard \& Kitchin (eds), 2011:108). More specifically, people use the bodies for a space of interaction by creating special forms of sociality in urban spaces. All these different forms of action that are clearly shaped through the city streets pose practical forms of resistance that cannot be conceptualized and emerge as criticism of bureaucracy that designs from above. Therefore, "if it is true that forests of gestures are manifest in the streets, their movement cannot be captured in a picture, nor can the meaning of their movements be circumscribed in a text" (De Certeau, 1984: 103). However, urban residents

\footnotetext{
2 "De Certeau proposed making a distinction between place and space as a basis for a set of analytical tools: only by the activities and dealings of the actors would (inanimate) places be transformed into spaces" -Rau S., Schönherr E. (Eds) (2014). Mapping Spatial Relations, Their Perceptions and Dynamics. Switzerland: Springer, pp. 141
}

3 "Strategy claims territory and defines place; tactics use and subvert those places" - Hubbard, P., \& Kitchin R. (Eds) (2011). Key Thinkers on Space and Place. London: Sage Publications Ltd, pp.108 
need to negotiate practically between opportunities and problems in the city. This situation shows that the city does not meet the needs of all residents' activities or conditions associated with them. Specifically, if we analyze the urban design of Tirana, especially after the 90 s, we note (e.g. from a perspective of people with special abilities) that the city is characterized by an impossibility of physical access or exclusion by exposing certain categories of individuals (the elderly, people with physical disabilities, etc.) to social exclusion and the risks of physical injury. Drafting public space proves that individuals who have problems with physical movements do not find their needs expressed. For example, those with visual problems do not have the facilities of special road signs. One of the consequences of this situation is related to the fact that architects and urban planners exclude these individuals in everyday living spaces by disembodying the city. Their use of the classical method of planning and designing from far and above has conceived the city as a mechanical whole that can be easily and immediately understood. In this view, the city appears as homogeneous and does not include different needs and preferences of populations. But "designing for diversity includes the design of urban services and amenities for a range of populations with different needs and preferences, and of non-exclusionary shared spaces and services that might be used in common (if not in exactly the same ways) across lines of cultural, class and generational difference" (Tonkiss, 2013: 165).

Meanwhile, at a more general level, different scholars emphasize that there are important links between regimes and exercise of power. Often, the official views of the city (maps, censuses, plans, etc.) draw the city from a technical and too bureaucratic point of view. Given this practice, De Certeau is extremely critical in pointing out that this type of urban space view simplifies reality by looking at the latter only as an exchange value (physical and economic units) and not as a value in social use. ".... the places of social space are very different from those of natural space in that they are not simply juxtaposed: they may be intercalated, combined, superimposed - they may even sometimes collide (Lefebvre, 1991: 88). Realistically, the different urban forms (roads, squares, etc.) are signs of an individual and collective memory, rejecting their formal meaning (means of passing between different spaces). As Knox also points out, there exists a ".... relationship between urban spaces and their inhabitants, and it also has a lot to do with aesthetics and identity. It is this: people 'manage' several distinct roles or identities at once. This is particularly characteristic of urban environments because of the physical and functional separation of the 'audiences' to which different roles are addressed" (Knox, 2011: 35)

\section{Conclusions}

There are many ways of perceiving and conceiving the city depending on the perspective or the theory applied to this purpose. The case of Tirana has been considered from the aspect that it is traditionally 'built' from the classic point of view of the so-called theory of representation, which projects the urban space in abstract and mechanical terms, ignoring the practices and dynamics of the daily activities of the inhabitants. In this sense, the city has excluded or hindered the life activities of its inhabitants because it has not substantially considered their concrete interests. In this regard, a new approach to conception and perception of the city is born as a critique of the created situation, based on concrete and real practices of the inhabitants, focusing their needs. The body and practices of everyday life has become the main vectors through which the city is understood with all the dynamics and practices it creates and interprets.

\section{References}

Amin A., Thrift N. (2002). Cities. Reimagining the urban. Oxford: Blackwell

De Certeau, M. (1984).The Practice Of Everyday Life. Berkeley: University of California Press

Hall T., Hubbard P. and Short J. (2008) Companion to the City. London: Sage Publications Ltd

Henckel D., Thomaier S., Könecke B., Zedda R., Stabilini S. (Eds.) (2013). Space -Time Design of the Public City. Springer: Netherlands

Hubbard, P., \& Kitchin R. (Eds) (2011). Key Thinkers on Space and Place. London: Sage Publications Ltd

Inam A. (2014). Designing Urban Transformation. New York : Routledge

Knox P. (2011). Cities, Design and Urban Life. New York: Routledge 
Lefebvre, H. (1991). The Production of Space. Oxford UK: Blackwell Publishing Lefebvre, H. (1996). Writings on the Cities. Oxford UK: Blackwell Publishing

Rau S., Schönherr E. (Eds) (2014). Mapping Spatial Relations, Their Perceptions and Dynamics. Switzerland: Springer

Tonkiss F. (2013). Cities by Design. The Social Life of Urban Form. UK: Polity Press

Ward, G. (2000). The Certeau Reader. Oxford UK: Blackwell Publishing 